
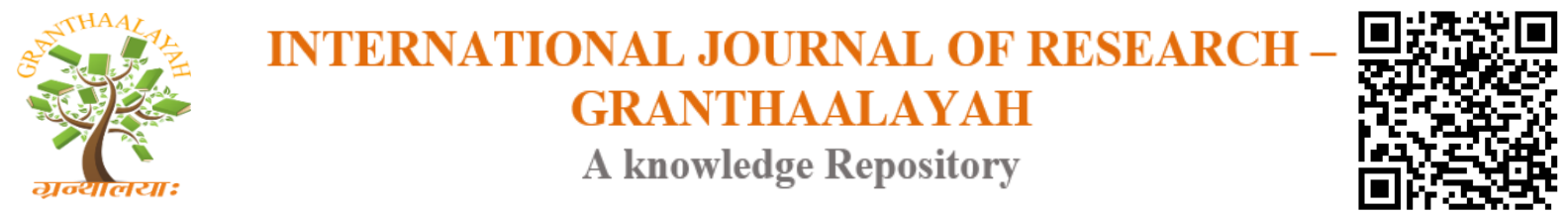

Science

\title{
ACTIVE POWER LOSS REDUCTION \& STATIC VOLTAGE STABILITY MARGIN ENHANCEMENT BY AERIFORM NEBULA ALGORITHM
}

\author{
Dr.K.Lenin ${ }^{* 1}$ \\ ${ }^{* 1}$ Professor Prasad V. Potluri Siddhartha Institute of Technology Kanuru, Vijayawada, Andhra \\ Pradesh -520007, India
}

\begin{abstract}
In this paper, Aeriform Nebula Algorithm (ANA) has been used for solving the optimal reactive power dispatch problem. Aeriform Nebula Algorithm (ANA) is stirred from the deeds of cloud. ANA imitate the creation behavior, modify behavior and expand deeds of cloud. The projected Aeriform Nebula Algorithm (ANA) has been tested on standard IEEE 30 bus test system and simulation results shows clearly about the superior performance of the proposed Aeriform Nebula Algorithm (ANA) in reducing the real power loss and voltage stability has been enhanced.
\end{abstract}

Keywords: Optimal Reactive Power; Transmission Loss; Aeriform Nebula; Nature -Inspired Algorithm.

Cite This Article: Dr.K.Lenin. (2017). “ACTIVE POWER LOSS REDUCTION \& STATIC VOLTAGE STABILITY MARGIN ENHANCEMENT BY AERIFORM NEBULA ALGORITHM." International Journal of Research - Granthaalayah, 5(10), 375-389. https://doi.org/10.29121/granthaalayah.v5.i10.2017.2316.

\section{Introduction}

Main objective of the Optimal reactive power dispatch problem is to minimize the real power loss and to enhance the voltage stability index.A variety ofnumerical techniqueslike the gradient method [1-2], Newton method [3] and linear programming [4-7] have been adopted to solve the optimal reactive power dispatch problem. Both the gradient and Newton methods has the complexity in controlling inequality constraints. If linear programming is applied, then the inputoutput function has to be articulated as a set of linear functions which predominantly lead to loss of accuracy. Thedifficulty of voltage stability and fall down, play a major role in power system planning and operation [8]. Global optimization has received wide-ranging research responsiveness, and enormousnumber of methods has been applied to solve this problem. Evolutionary algorithms such as genetic algorithm have been already proposed to solve the reactive power flow problem [9,10].Evolutionary algorithm is a heuristic approach used for minimization problems by utilizing nonlinear and non-differentiable incessant space functions. In [11], Genetic algorithm has been used to solve optimal reactive power flow problem. In [12], 
Hybrid differential evolution algorithm is proposed to perk up the voltage stability index. In [13],Biogeography Based algorithm is planned to solve the reactive power dispatch problem. In [14], afuzzy based method is used to solve the optimal reactive power scheduling method. In [15], an improved evolutionary programming is used to solvethe optimal reactive power dispatch problem. In [16], the optimal reactive power flow problem is solved by integrating a genetic algorithm with a nonlinearinterior point method. In [17], apattern algorithm is used to solve acdc optimal reactive powerflow model with the generator capability limits. In [18], proposes a two-step approach to evaluate Reactive power reserves with respect to operating constraints and voltage stability. In [19], a programming based proposed approach used to solve the optimal reactive power dispatch problem. In [20], presents aprobabilistic algorithm for optimal reactive power requirementin hybrid electricity markets with uncertain loads. In this paper, Aeriform Nebula Algorithm (ANA) has been used for solving the Optimal Reactive Power Dispatch (ORPD) Problem. Aeriform Nebula Algorithm (ANA) is stirred from the deeds of cloud. ANA imitate the creation behavior, modify behavior and expand deeds of cloud. In this algorithm a new - revolve round search method is presented. In which the entire population expand from the present optimal positions to the entire explore space in a cloud continuous existence pattern[2125], as a replacement for clustering from all directions to the optimal position. This individual optimization method can produce the Aeriform Nebula Algorithm (ANA) to conserve elevated population assortment and stop the algorithm from fence into local optimal solution. The proposed Aeriform Nebula Algorithm (ANA) has been evaluated in standard IEEE 30 bus test system \& the simulation results show that our proposed approach outperforms all reported algorithms in minimization of real power loss and voltage stability also enhanced.

\section{Voltage Stability Evaluation}

\subsection{Modal Analysis For Voltage Stability Evaluation}

Modal analysis is one among best methods for voltage stability enhancement in power systems. The steady state system power flow equations are given by.

$\left[\begin{array}{l}\Delta \mathrm{P} \\ \Delta \mathrm{Q}\end{array}\right]=\left[\begin{array}{cc}\mathrm{J}_{\mathrm{p} \theta} & \mathrm{J}_{\mathrm{pv}} \\ \mathrm{J}_{\mathrm{q} \theta} & \mathrm{J}_{\mathrm{QV}}\end{array}\right]\left[\begin{array}{l}\Delta \theta \\ \Delta V\end{array}\right]$

Where

$\Delta \mathrm{P}=$ Incremental change in bus real power.

$\Delta \mathrm{Q}=$ Incremental change in bus reactive Power injection

$\Delta \theta=$ incremental change in bus voltage angle.

$\Delta \mathrm{V}=$ Incremental change in bus voltage Magnitude

Jp $\theta$, JPV , JQ $\theta$, JQV jacobian matrix are the sub-matrixes of the System voltage stability is affected by both $\mathrm{P}$ and $\mathrm{Q}$.

To reduce (1), let $\Delta \mathrm{P}=0$, then.

$\Delta \mathrm{Q}=\left[\mathrm{J}_{\mathrm{QV}}-\mathrm{J}_{\mathrm{Q} \theta} \mathrm{J}_{\mathrm{P} \theta^{-1}} \mathrm{~J}_{\mathrm{PV}}\right] \Delta \mathrm{V}=\mathrm{J}_{\mathrm{R}} \Delta \mathrm{V}$

$\Delta \mathrm{V}=\mathrm{J}^{-1}-\Delta \mathrm{Q}$

Where

$\mathrm{J}_{\mathrm{R}}=\left(\mathrm{J}_{\mathrm{QV}}-\mathrm{J}_{\mathrm{Q} \theta} \mathrm{J}_{\mathrm{P} \theta^{-1}} \mathrm{JPV}\right)$ 
$\mathrm{J}_{\mathrm{R}}$ is called the reduced Jacobian matrix of the system.

\subsection{Modes of Voltage instability}

Voltage Stability characteristics of the system have been identified by computing the Eigen values and Eigen vectors.

Let

$\mathrm{J}_{\mathrm{R}}=\xi \wedge \eta$

Where,

$\xi=$ right eigenvector matrix of JR

$\eta=$ left eigenvector matrix of JR

$\Lambda=$ diagonal eigenvalue matrix of JR and

$\mathrm{J}_{\mathrm{R}^{-1}}=\xi \wedge^{-1} \eta$

From (5) and (8), we have

$\Delta \mathrm{V}=\xi \wedge^{-1} \eta \Delta \mathrm{Q}$

or

$\Delta \mathrm{V}=\sum_{\mathrm{I}} \frac{\xi_{\mathrm{i}} \eta_{\mathrm{i}}}{\lambda_{\mathrm{i}}} \Delta \mathrm{Q}$

Where $\xi \mathrm{i}$ is the ith column right eigenvector and $\eta$ the ith row left eigenvector of JR.

$\lambda \mathrm{i}$ is the ith Eigen value of JR.

The ith modal reactive power variation is,

$\Delta Q_{\mathrm{mi}}=\mathrm{K}_{\mathrm{i}} \xi_{\mathrm{i}}$

where,

$\mathrm{K}_{\mathrm{i}}=\sum_{\mathrm{j}} \xi_{\mathrm{ij}}-1$

Where

$\xi \mathrm{ji}$ is the jth element of $\xi \mathrm{i}$

The corresponding ith modal voltage variation is

$\Delta \mathrm{V}_{\mathrm{mi}}=\left[1 / \lambda_{\mathrm{i}}\right] \Delta \mathrm{Q}_{\mathrm{mi}}$

If $|\lambda \mathrm{i}|=0$ then the ith modal voltage will collapse.

In (10), let $\Delta \mathrm{Q}=\mathrm{ek}$ where ek has all its elements zero except the kth one being 1 . Then,

$\Delta \mathrm{V}=\sum_{\mathrm{i}} \frac{\eta_{1 \mathrm{k}} \xi_{1}}{\lambda_{1}}$

$\eta_{1 \mathrm{k}} \mathrm{k}$ th element of $\eta_{1}$

$\mathrm{V}-\mathrm{Q}$ sensitivity at bus $\mathrm{k}$

$\frac{\partial V_{\mathrm{K}}}{\partial \mathrm{Q}_{\mathrm{K}}}=\sum_{\mathrm{i}} \frac{\eta_{1 \mathrm{k}} \xi_{1}}{\lambda_{1}}=\sum_{\mathrm{i}} \frac{\mathrm{P}_{\mathrm{ki}}}{\lambda_{1}}$

\section{Problem Formulation}

The objectives of the reactive power dispatch problem is to minimize the system real power loss and maximize the static voltage stability margins (SVSM). 


\subsection{Minimization of Real Power Loss}

Minimization of the real power loss (Ploss) in transmission lines is mathematically stated as follows.

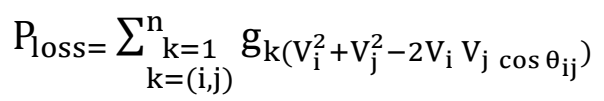

Where $\mathrm{n}$ is the number of transmission lines, gk is the conductance of branch $\mathrm{k}, \mathrm{Vi}$ and $\mathrm{Vj}$ are voltage magnitude at bus $\mathrm{i}$ and bus $\mathrm{j}$, and $\theta \mathrm{ij}$ is the voltage angle difference between bus $\mathrm{i}$ and bus $\mathrm{j}$.

\subsection{Minimization of Voltage Deviation}

Minimization of the voltage deviation magnitudes (VD) at load buses is mathematically stated as follows.

Minimize VD $=\sum_{\mathrm{k}=1}^{\mathrm{nl}}\left|\mathrm{V}_{\mathrm{k}}-1.0\right|$

Where $\mathrm{nl}$ is the number of load busses and $\mathrm{Vk}$ is the voltage magnitude at bus $\mathrm{k}$.

\subsection{System Constraints}

Objective functions are subjected to these constraints shown below.

Load flow equality constraints:

$P_{G i}-P_{D i}-V_{i} \sum_{j=1}^{n b} V_{j}\left[\begin{array}{cc}G_{i j} & \cos \theta_{i j} \\ +B_{i j} & \sin \theta_{i j}\end{array}\right]=0, i=1,2 \ldots, n b$

$Q_{G i}-Q_{D i}-V_{i \sum_{j=1}^{n b} V_{j}}\left[\begin{array}{cc}G_{i j} & \sin \theta_{i j} \\ +B_{i j} & \cos \theta_{i j}\end{array}\right]=0, i=1,2 \ldots, n b$

where, nb is the number of buses, PG and QG are the real and reactive power of the generator, PD and QD are the real and reactive load of the generator, and Gij and Bij are the mutual conductance and susceptance between bus $\mathrm{i}$ and bus $\mathrm{j}$.

Generator bus voltage (VGi) inequality constraint:

$\mathrm{V}_{\mathrm{Gi}}^{\min } \leq \mathrm{V}_{\mathrm{Gi}} \leq \mathrm{V}_{\mathrm{Gi}}^{\max }, \mathrm{i} \in \mathrm{ng}$

Load bus voltage (VLi) inequality constraint:

$\mathrm{V}_{\mathrm{Li}}^{\min } \leq \mathrm{V}_{\mathrm{Li}} \leq \mathrm{V}_{\mathrm{Li}}^{\max }, \mathrm{i} \in \mathrm{nl}$

Switchable reactive power compensations (QCi) inequality constraint:

$\mathrm{Q}_{\mathrm{Ci}}^{\min } \leq \mathrm{Q}_{\mathrm{Ci}} \leq \mathrm{Q}_{\mathrm{Ci}}^{\max }, \mathrm{i} \in \mathrm{nc}$

Reactive power generation (QGi) inequality constraint:

$\mathrm{Q}_{\mathrm{Gi}}^{\min } \leq \mathrm{Q}_{\mathrm{Gi}} \leq \mathrm{Q}_{\mathrm{Gi}}^{\max }, \mathrm{i} \in \mathrm{ng}$

Transformers tap setting (Ti) inequality constraint:

$\mathrm{T}_{\mathrm{i}}^{\min } \leq \mathrm{T}_{\mathrm{i}} \leq \mathrm{T}_{\mathrm{i}}^{\text {max }}, \mathrm{i} \in \mathrm{nt}$

Transmission line flow (SLi) inequality constraint:

$\mathrm{S}_{\mathrm{Li}}^{\min } \leq \mathrm{S}_{\mathrm{Li}}^{\max }, \mathrm{i} \in \mathrm{nl}$ 
Where, nc, ng and nt are numbers of the switchable reactive power sources, generators and transformers.

\section{Aeriform Nebula Algorithm (ANA)}

Aeriform Nebula Algorithm (ANA) is stirred from the deeds of cloud. ANA imitate the creation behavior, modify behavior and expand deeds of cloud. Clouds are anall over part of our planet. Because of the multifaceted generationprocedure and the impermanence of transform, cloud has a multi-colouredlook and ever-changing attribute.Basically the cloud is water droplets condensed by water vapour in the air, super cooled water droplets, ice crystals or a perceptible suspension in mixture of them. Convective clouds form when moist air iswarmed and becomes buoyant. The air raises-haulage water vapour with it and expands, get cooled as it goes on. In view of the fact that the temperature and pressure of the air decrease, its saturation point, equilibriumpoint of evaporation and condensation has been reduced. When the water vapour content of the growing air becomes superior to its saturationpoint, then condensation occurs, which yield the miniature condensed cloud waterparticles. The water particles acquirejointly and hang in the air by the gatherpowerof updraft, and form clouds what we observe in the sky. But stratus clouds oftenform, whenoodlesof warm and cool air combine due to lifting of the air over terrain. Although the generation process, self-motivated movement process, extend andrevival processes of cloud are multifaceted in the nature, if we see just from amacroscopic view it can be easy: Firstly, the earth can be considered asawhole spacesimply composed of many disjoint areas, and every area has its own humidity valueand air pressure value. According to universalinformation we know that area withhigher humidity value would produce clouds with higher potential, and the air pressure dissimilarity between areas generates airflow and under the action of which thegenerated clouds would utter to the areas with low air pressure, and they mightget together or extend according to the air pressure of close by areas in the shiftprocess. By simulating the generation behaviour, shiftbehaviour and extendbehaviour of cloud, this paper proposes a new optimization Aeriform Nebula Algorithm (ANA) for Solving optimal reactive power dispatch problem.

Aeriform Nebula Algorithm (ANA) is stirred from the deeds of cloud. ANA imitate the creation behavior, modify behavior and expand deeds of cloud.

The process of Aeriform Nebula Algorithm (ANA) is described as follows:

i. Theabsolute search space is divided into numerous disjoint regions according to the specified rules, and every region has its own humidity value and air pressure value.

ii. The performance of clouds should follow set of lawsas scheduled below:

a. Clouds are able to be generated in regions whose dampness values are higher than one exact threshold.

b. Beneath the endeavour of wind, clouds move from regions with enhanced air pressure value to regions with lower air pressure value.

c. In the moving procedure, the droplets of one cloud would extend or acquirejointly according to the air pressure difference between the region where this cloud locateearlier thanshift behaviour and region where cloud locates subsequent toshift behaviour. 
d. One cloud is regarded as departed, when its revelation exceeds a specific value or its droplets number is less than a specific value.

iii. The humidity value and air pressure value of all regions are rationalizedeach time after the generation behaviour, shift behaviour and extend behaviour of clouds.

The metaphors of prime concepts in Aeriform Nebula Algorithm (ANA) is as follows, Suppose $\mathrm{U}$ is the cosmos, the region is defined as subspace after the parting of $\mathrm{U}$ according to some system. Every dimension of $\mathrm{U}$ is divided into $\mathrm{M}$ small intervals

$$
I_{i}=\frac{\left(u_{i}-l_{i}\right)}{M}, i=1,2, \ldots, D
$$

Where $I_{i}$ is the length of interval in ith dimension, $u_{i}$ and $l_{i}$ express the upper boundary and lower boundary of $\mathrm{i}$ dimension respectively, $\mathrm{D}$ is the dimension. Then the total search space would be split into MD regions, and each of them meet the following properties:

$$
\left\{\begin{array}{c}
U_{i=1}^{M^{D}} U_{i}=U \\
U_{i} \cap U_{j}=\emptyset, \forall i, j \in\left\{1,2, \ldots, M^{D}\right\}, I \neq j
\end{array}\right.
$$

Cloud $\mathrm{C}$ is defined as a qualitative perception in $\mathrm{U}$, and $\mathrm{x}$ is the stochastic execution of $\mathrm{C}, \mathrm{x} \in \mathrm{U}$. Each $\mathrm{x}$ is called one cloud droplet, and the allocation of $\mathrm{x}$ in $\mathrm{U}$ is called cloud. In this paper the perception of cloud is described by the normal cloud model. So the qualitative feature of one cloud can be described by the three digital character (Ex, En, He) and the droplets number $n$, where Ex (Expected value), En (Entropy) and He (Hyper entropy) of one cloud articulate the centre position of cloud, the cover range of cloud and the thickness of cloud correspondingly.

Presume there are $\mathrm{m}$ clouds in iteration $\mathrm{t}$, the term of which is:

$$
\mathrm{C}^{\mathrm{t}}=\left\{\mathrm{C}_{1}^{\mathrm{t}}, \mathrm{C}_{2}^{\mathrm{t}}, \ldots, \mathrm{C}_{\mathrm{j}}^{\mathrm{t}}, \ldots, \mathrm{C}_{\mathrm{m}}^{\mathrm{t}}\right\}
$$

The droplets numbers of clouds can be articulated as

$\mathrm{n}^{\mathrm{t}}=\left\{\mathrm{n}_{1}^{\mathrm{t}}, \mathrm{n}_{2}^{\mathrm{t}}, \ldots, \mathrm{n}_{\mathrm{j}}^{\mathrm{t}}, \ldots, \mathrm{n}_{\mathrm{m}}^{\mathrm{t}}\right\}$

The droplets numbers of all clouds must convene the two properties listed below:

$$
\left\{\begin{array}{l}
\mathrm{n}_{\mathrm{j}}>d N, \quad \forall j=1,2, \ldots, m \\
\sum_{\mathrm{j}=1}^{\mathrm{m}} \mathrm{n}_{\mathrm{j}} \leq \mathrm{N}
\end{array}\right.
$$

Where $\mathrm{dN}$ express the smallest value of the droplets number in one cloud, $\mathrm{N}$ express maximum value of droplets number in every iteration. For the communicative expediency the three digital characteristics $(\mathrm{Ex}, \mathrm{En}, \mathrm{He})$ of one cloud is marked as $\mathrm{C} \cdot \mathrm{Ex}, \mathrm{C} \cdot \mathrm{En}, \mathrm{C} \cdot \mathrm{He}$. The droplets allocation of one cloud can be articulated as:

$$
\mathrm{C}(\mathrm{x}) \sim \mathrm{N}\left(\mathrm{C} \cdot \mathrm{Ex}, \mathrm{En}^{\prime 2}\right)
$$


WhereEn' $\sim \mathrm{N}\left(\mathrm{C} \cdot \mathrm{En},(\mathrm{C} \cdot \mathrm{He})^{2}\right), \mathrm{N}\left(\mathrm{C} \cdot \mathrm{En},(\mathrm{C} \cdot \mathrm{He})^{2}\right)$ expresscriterion normal random variable when $\mathrm{C} \cdot \mathrm{En}$ indicates the prospect, $(\mathrm{C} \cdot \mathrm{He})^{2}$ is the variance. Each region has its humidity value and air pressure value.

The dampness value of one region is defined as the best fitness value found in this region so far, the expression of which is

$$
X_{i}^{*}=\underset{x \in U_{i}}{\arg \max f(x), H_{i}} f\left(X_{i}^{*}\right)
$$

Where $\mathrm{f}$ is the objective function; $\mathrm{x}$ express the droplets which dropped into region $\mathrm{U}_{\mathrm{i}}$ once, $\mathrm{X}_{\mathrm{i}}^{*}$ indicates the position with the maximum fitness value and articulate the humidity value of region $\mathrm{U}_{\mathrm{i}}$.

The air pressure value of one region is defined as how much period this region has been searched, which is articulated as:

$P_{i}=\operatorname{CNT}\left(x \in U_{i}\right), i=1,2, \ldots, M^{D}$

Where CNT function is used to do the statistics of data meeting the obligation.

In the initialization segment, Aeriform Nebula Algorithm (ANA) is chiefly to attain the region separation, the initialization of the dampness values and air pressure values of regions, and the limit settings, including threshold factor $\lambda$, contract factor $\xi$, weaken rate $\gamma$,. The initialization of the dampness value and the air pressure value of regions is accomplished by disperse the population in the search space arbitrarily and the humidity value and air pressure value of regions are initialized by Equations (30) and (31) correspondingly.

Based on the imaginary information of normal cloud model, we recognize that normal cloud can be generated when the three digital features $(\mathrm{Ex}, \mathrm{En}, \mathrm{He})$ and droplets numbers are prearranged. In this paper, the influence of the super-entropy is ignored, so we assume He as constant and it is set as $\mathrm{He}=0.001$. Then there are three parameters required to be confirmed earlier than the generation process: (a) the regions where clouds can be generated, and then the middle position Ex can be established; (b) entropy En, which is used to settle on the exposure of one cloud; (c) the droplets figure, which determine the dimension of cloud.

In this paper, we presume that no more than the regions whose dampness values are superior to a threshold value can generate cloud.

The computational principle of the threshold value is expressed as follows:

$$
\mathrm{Ht}=\mathrm{H}_{\min }+\lambda^{*}\left(\mathrm{H}_{\max }-\mathrm{H}_{\min }\right)
$$

Where $\mathrm{H}_{\min }$ and $\mathrm{H}_{\max }$ express the minimum and maximum dampness values of the whole search space respectively; $\lambda$ is threshold factor. Then the regions where clouds can be generated can be articulated by the set $\mathrm{R}=\left\{\mathrm{i} \mid \mathrm{H}_{\mathrm{i}}>H t, i=1,2, \ldots, \mathrm{M}^{\mathrm{D}}\right\}$. The value of $\lambda$ determine the regions in which clouds can be generated and the droplets number of cloud recently generated. If $\lambda$ is set 
too large, the number of regions where clouds can be generated in is so littleand that will cause enthralled into local optimum of Aeriform Nebula Algorithm (ANA). When $\lambda$ is set too small, there will be too many regions that can generate clouds. This observable fact will goin opposition to the convergence of Aeriform Nebula Algorithm (ANA). So the setting of $\lambda$ is vital and we set it as $\lambda=0.701$ in this paper.

For the cause of advancing the convergenceprecision in Aeriform Nebula Algorithm (ANA), the paper presumes the initial entropy value of one cloud newly generated decrease with iterations. Firstly, the initial entropy value EnMo is defined as:

$$
E n M o=\frac{\mathrm{I} / \mathrm{M}}{\mathrm{A}}
$$

Where I is the length of explore space; A determines the early coverage of the cloud. According to the 3En rule of normal cloud model, we set $A=6$ in this paper, which means the cloud generated in the first time can cover one area approximately.

The value of EnM decreases in a non-linear model with iterations, the expression is given as,

$$
\mathrm{EnM}^{\mathrm{t}}=\mathrm{EnM}^{0} \times \xi
$$

Where $\xi$ is contract factor $0<\xi<1$.

Presume the greatest number of droplets in the explore space at one time is a steady value $\mathrm{N}$ and the droplets numbers of clouds recently generated in diverse regions are related with the humidity values of these regions: upper humidity with more droplets, and lower humidity with fewer droplets.

The total number of droplets can be newly generated in current iteration marked as $\mathrm{nNew}$, the expression of which is:

$\mathrm{nNew}=\mathrm{N}-\sum_{\mathrm{j}=1}^{\mathrm{m}} \mathrm{n}_{\mathrm{j}}^{\mathrm{t}}$

Where $\mathrm{N}$ is the maximum value of droplets number in every iteration; $\mathrm{m}$ is the number of clouds existed in iteration $t ; n_{j}^{t}$ is the droplets number of cloud $C_{j}^{t}$ in the th iteration. As mentioned in the explanation of cloud, the droplets number of one cloud must be greater than a steady value $\mathrm{dN}$, or else it will be regarded as departed. So if the nNew calculated by Eq. (35) is less than dN, there is no cloud is generated this time, if not we can then determine the droplets number of each cloud.

Presume that the set $\mathrm{R}=\left\{\mathrm{i} \mid \mathrm{H}_{\mathrm{i}}>H t, i=1,2, \ldots, \mathrm{M}^{\mathrm{D}}\right\}$ has $\mathrm{k}$ elements, the clouds newly generated are, $\mathrm{C}_{\mathrm{m}+1}^{\mathrm{t}} \cdot \mathrm{C}_{\mathrm{m}+2}^{\mathrm{t}}, ., \mathrm{C}_{\mathrm{m}+\mathrm{j}}^{\mathrm{t}}, \ldots, \mathrm{C}_{\mathrm{m}+\mathrm{k}}^{\mathrm{t}}$. The droplets number of cloud recently generated has a comparative relation with the humidity of regions in $\mathrm{R}$, as givenin Eq. (36).

$$
\mathrm{n}_{\mathrm{m}+\mathrm{j}}^{\mathrm{t}}=\frac{\mathrm{H}_{\mathrm{R}(\mathrm{j})}}{\sum_{\mathrm{j}=1}^{\mathrm{k}} \mathrm{H}_{\mathrm{R}(\mathrm{j})}} \times \mathrm{nNew}
$$


Where $\mathrm{j}=1,2, \ldots, \mathrm{j} ; \mathrm{H}_{\mathrm{R}(\mathrm{j})}$ is the humidity value of region $\mathrm{R}(\mathrm{j})$.

After calculating the droplets number of each cloud newly generated, check out all the values, if there is one or more $n_{m+j}<d N, 0<j \leq k$, remove the element with least humidity rate in $R$. Then recalculate the droplets number of each cloud until all the droplets numbers are superior than $\mathrm{dN}$.

The numeral features of clouds newly generated can be expressed as

$\mathrm{C}_{\mathrm{m}+\mathrm{j}}^{\mathrm{t}} \cdot \mathrm{Ex}=\mathrm{X}_{\mathrm{s}(\mathrm{j})}^{*}, \mathrm{C}_{\mathrm{m}+\mathrm{j}}^{\mathrm{t}} \cdot \mathrm{En}=\mathrm{EnM}^{\mathrm{t}}, \mathrm{C}_{\mathrm{m}+\mathrm{j}}^{\mathrm{t}} \cdot \mathrm{He}=\mathrm{He}, 0<j \leq k$.

Presume the region where the cloud $c_{j}^{t}(j=1,2, \ldots, m)$ locates is US, randomly select one region whose air pressure value is lower than $U_{S}^{\prime} S$ as the target region UT . The pressure differentiation between US and UT is $\Delta \mathrm{P}=\mathrm{P}_{\mathrm{S}}-\mathrm{P}_{\mathrm{T}}$. The update equation of cloud's location is expressed as:

$$
\mathrm{C}_{\mathrm{j}}^{\mathrm{t}+1} \cdot \mathrm{Ex}=\mathrm{C}_{\mathrm{j}}^{\mathrm{t}} \cdot \mathrm{Ex}+\overrightarrow{\mathrm{V}}_{\mathrm{j}}^{\mathrm{t}+1}, 0<j \leq m
$$

The shift velocity of cloud can be expressed as follows,

$\overrightarrow{\mathrm{V}}_{\mathrm{j}}^{\mathrm{t}+1}=\overrightarrow{\mathrm{e}} \times 6 \times \mathrm{C}_{\mathrm{j}}^{\mathrm{t}} \cdot \mathrm{En}$

Where $\vec{e}$ expresses the direction of movement and $\vec{e}$ can be calculated as follows,

$\vec{e}=\frac{(1-\beta) \times \vec{V}_{j}^{t}+\beta \times\left(X_{T}^{*}-C_{j}^{t} \cdot E x\right)}{\left\|(1-\beta) \times \vec{V}_{j}^{t}+\beta \times\left(X_{T}^{*}-C_{j}^{t} \cdot E x\right)\right\|}$

Where $\beta$ is air pressure factor and can be calculated as $\beta=\frac{\Delta p}{P_{\max }-p_{\min }}$

Where $\mathrm{P}_{\max }$ is the maximum air pressure differentiation of the search space so far and $\mathrm{P}_{\min }$ is the least amount one. The value of $\beta$ indicates the influence degree of air pressure difference on the move velocity of cloud; the fitness value of $\mathrm{X}_{\mathrm{T}}^{*}$ indicates the humidity value within the region UT.

Due to the disappearance or collide between clouds in the move process the energy of cloud would reduce, so this paper propose a perception of weaken rate $\gamma$, which means the droplets number of each cloud will decrease $\gamma \times 100 \%$ after each iteration.

The update expression of droplets number is:

$$
\mathrm{n}_{\mathrm{j}}^{\mathrm{t}+1}=\mathrm{n}_{\mathrm{j}}^{\mathrm{t}} \times(1-\gamma) 0<j \leq m
$$

If the droplets number of cloud is less than $\mathrm{dN}$ after this step, it is regarded as degenerate. The $\gamma$ is mainly used to determine the moved out speed of clouds, and the set of it is very important. Because a large value of $\gamma$ will lead to the diminishing of clouds before they left far away from the regions where they are generated, the global explore ability of Aeriform Nebula Algorithm (ANA) will be appalling; while when the value of $\gamma$ is very small, the sustainedcontinuation time 
of cloud will be so long that the number of clouds newly generated will be too few, which may put shortcoming to the convergence of Aeriform Nebula Algorithm (ANA). In this paper we put $\gamma=0.20$.

Presume the region where the cloud $c_{j}^{t}(j=1,2, \ldots, m)$ locates is US, and the region where cloud will locate after the move process is UT. If UT $\neq$ US, the extend swiftness of cloud is expressed as:

$\mathrm{C}_{\mathrm{j}}^{\mathrm{t}+1} \cdot \mathrm{En}=\mathrm{C}_{\mathrm{j}}^{\mathrm{t}} \cdot \mathrm{En} \times(1+\alpha)$

Where $\alpha$ is extend factor and it can be designed as,

$\alpha=\frac{\Delta \mathrm{P}}{\mathrm{P}_{\max }}$

Where Pmax is the maximum air pressure difference in the search space; $\Delta \mathrm{P}=\mathrm{P}_{\mathrm{S}}-\mathrm{P}_{\mathrm{T}}$ is the pressure difference between US and UT. If UT $=\mathrm{US}$, the cloudC $\mathrm{C}_{\mathrm{j}}^{\mathrm{t}}$ will extend according to the greatest pressure difference between US and tangential regions, the extend expression is as same as Eq. (43). Aeriform Nebula Algorithm (ANA) updates the dampness values and air pressure values of all regions every time after the generation process of cloud, the cloud's shift process and extend process.

\subsection{Aeriform Nebula Algorithm (ANA) for Solving Optimal Reactive Power Dispatch Problem}
a. Start
b. Initialization
c. Generation of Cloud
d. Update The Humidity Value And Air Pressure Value of Region
e. The Shift Behaviour of Cloud
f. The Extend Behaviour of Cloud
g. Update The Humidity Value And Air Pressure Value of Region
h. End of Loop? If Yes End or Go To Step c

\section{Simulation Results}

The efficiency of the proposed Aeriform Nebula Algorithm (ANA) is demonstrated by testing it on standard IEEE-30 bus system. The IEEE-30 bus system has 6 generator buses, 24 load buses and 41 transmission lines of which four branches are (6-9), (6-10), (4-12) and (28-27) - are with the tap setting transformers. The lower voltage magnitude limits at all buses are 0.95 p.u. and the upper limits are 1.1 for all the PV buses and 1.05 p.u. for all the PQ buses and the reference bus. The simulation results have been presented in Tables 1,2, $3 \& 4$. And in the Table 5 shows the proposed algorithm powerfully reduces the real power losses when compared to other given algorithms. The optimal values of the control variables along with the minimum loss obtained are given in Table 1. Corresponding to this control variable setting, it was found that there are no limit violations in any of the state variables. 
Table 1: Results of ANA - ORPD optimal control variables

\begin{tabular}{|l|l|}
\hline Control variables & Variable setting \\
\hline V1 & 1.042 \\
V2 & 1.043 \\
V5 & 1.044 \\
V8 & 1.031 \\
V11 & 1.000 \\
V13 & 1.031 \\
T11 & 1.00 \\
T12 & 1.00 \\
T15 & 1.00 \\
T36 & 1.01 \\
Qc10 & 2 \\
Qc12 & 2 \\
Qc15 & 2 \\
Qc17 & 0 \\
Qc20 & 2 \\
Qc23 & 2 \\
Qc24 & 3 \\
Qc29 & 2 \\
Real power loss & 4.2712 \\
SVSM & \\
\hline
\end{tabular}

Optimal Reactive Power Dispatch (ORPD) problem together with voltage stability constraint problem was handled in this case as a multi-objective optimization problem where both power loss and maximum voltage stability margin of the system were optimized simultaneously. Table 2 indicates the optimal values of these control variables. Also it is found that there are no limit violations of the state variables. It indicates the voltage stability index has increased from 0.2476 to 0.2489 , an advance in the system voltage stability. To determine the voltage security of the system, contingency analysis was conducted using the control variable setting obtained in case 1 and case 2. The Eigen values equivalents to the four critical contingencies are given in Table 3. From this result it is observed that the Eigen value has been improved considerably for all contingencies in the second case.

Table 2: Results of ANA -Voltage Stability Control Reactive Power Dispatch (VSCRPD) Optimal Control Variables

\begin{tabular}{|l|l|}
\hline Control Variables & Variable Setting \\
\hline V1 & 1.048 \\
V2 & 1.047 \\
V5 & 1.049 \\
V8 & 1.034 \\
V11 & 1.005 \\
V13 & 1.038 \\
T11 & 0.090 \\
T12 & 0.090 \\
T15 & 0.090 \\
\hline
\end{tabular}




\begin{tabular}{|l|l|}
\hline T36 & 0.090 \\
Qc10 & 3 \\
Qc12 & 2 \\
Qc15 & 2 \\
Qc17 & 3 \\
Qc20 & 0 \\
Qc23 & 2 \\
\hline Qc24 & 2 \\
Qc29 & 3 \\
Real power loss & 4.9886 \\
SVSM & 0.2489 \\
\hline
\end{tabular}

Table 3: Voltage Stability under Contingency State

\begin{tabular}{|l|l|l|l|}
\hline Sl.No & Contingency & ORPD Setting & VSCRPD Setting \\
\hline 1 & $28-27$ & 0.1419 & 0.1434 \\
\hline 2 & $4-12$ & 0.1642 & 0.1650 \\
\hline 3 & $1-3$ & 0.1761 & 0.1772 \\
\hline 4 & $2-4$ & 0.2022 & 0.2043 \\
\hline
\end{tabular}

Table 4: Limit Violation Checking Of State Variables

\begin{tabular}{|l|l|l|l|l|}
\hline \multirow{2}{*}{$\begin{array}{c}\text { State } \\
\text { variables }\end{array}$} & \multicolumn{2}{|c|}{ Limits } & \multirow{2}{*}{ ORPD } & \multirow{2}{*}{ VSCRPD } \\
\cline { 2 - 3 } Q1 & Lower & Upper & & \\
\hline Q2 & -20 & 152 & 1.3422 & -1.3269 \\
\hline Q5 & -20 & 61 & 8.9900 & 9.8232 \\
\hline Q8 & -15 & 49.92 & 25.920 & 26.001 \\
\hline Q11 & -10 & 63.52 & 38.8200 & 40.802 \\
\hline Q13 & -15 & 42 & 2.9300 & 5.002 \\
\hline V3 & -15 & 48 & 8.1025 & 6.033 \\
\hline V4 & 0.95 & 1.05 & 1.0372 & 1.0392 \\
\hline V6 & 0.95 & 1.05 & 1.0307 & 1.0328 \\
\hline V7 & 0.95 & 1.05 & 1.0282 & 1.0298 \\
\hline V9 & 0.95 & 1.05 & 1.0462 & 1.0412 \\
\hline V10 & 0.95 & 1.05 & 1.0482 & 1.0498 \\
\hline V12 & 0.95 & 1.05 & 1.0400 & 1.0466 \\
\hline V14 & 0.95 & 1.05 & 1.0474 & 1.0443 \\
\hline V15 & 0.95 & 1.05 & 1.0457 & 1.0413 \\
\hline V16 & 0.95 & 1.05 & 1.0426 & 1.0405 \\
\hline V17 & 0.95 & 1.05 & 1.0382 & 1.0396 \\
\hline V18 & 0.95 & 1.05 & 1.0392 & 1.0400 \\
\hline V19 & 0.95 & 1.05 & 1.0381 & 1.0394 \\
\hline V20 & 0.95 & 1.05 & 1.0112 & 1.0194 \\
\hline V21 & 0.95 & 1.05 & 1.0435 & 1.0243 \\
\hline V22 & 0.95 & 1.05 & 1.0448 & 1.0396 \\
\hline
\end{tabular}




\begin{tabular}{|l|l|l|l|l|}
\hline V23 & 0.95 & 1.05 & 1.0472 & 1.0372 \\
\hline V24 & 0.95 & 1.05 & 1.0484 & 1.0372 \\
\hline V25 & 0.95 & 1.05 & 1.0142 & 1.0192 \\
\hline V26 & 0.95 & 1.05 & 1.0494 & 1.0422 \\
\hline V27 & 0.95 & 1.05 & 1.0472 & 1.0452 \\
\hline V28 & 0.95 & 1.05 & 1.0243 & 1.0283 \\
\hline V29 & 0.95 & 1.05 & 1.0439 & 1.0419 \\
\hline V30 & 0.95 & 1.05 & 1.0418 & 1.0397 \\
\hline
\end{tabular}

Table 5: Comparison of Real Power Loss

\begin{tabular}{|l|l|}
\hline Method & Minimum loss \\
\hline Evolutionary programming [26] & 5.0159 \\
\hline Genetic algorithm [27] & 4.665 \\
\hline Real coded GA with Lindex as SVSM [28] & 4.568 \\
\hline Real coded genetic algorithm [29] & 4.5015 \\
\hline Proposed ANA method & 4.2712 \\
\hline
\end{tabular}

\section{Conclusion}

In this paper, the Aeriform Nebula Algorithm (ANA) has been productively solved the Optimal reactive power dispatch problem problem. The key advantages of the Aeriform Nebula Algorithm (ANA) to the problem are optimization of different type of objective function, real coding of both continuous discrete control variables \& without any difficulty of handling nonlinear constraints. Aeriform Nebula Algorithm (ANA) is stirred from the deeds of cloud. ANA imitate the creation behavior, modify behavior and expand deeds of cloud. The projected Aeriform Nebula Algorithm (ANA) has been tested on standard IEEE 30 bus test system and simulation results shows clearly about the superior performance of the proposed Aeriform Nebula Algorithm (ANA) in reducing the real power loss and voltage stability has been enhanced.

\section{References}

[1] O.Alsac, B. Scott, "Optimal load flow with steady state security", IEEE Transaction. PAS -1973, pp. 745-751.

[2] Lee K Y , Paru Y M , Oritz J L -A united approach to optimal real and reactive power dispatch , IEEE Transactions on power Apparatus and systems 1985: PAS-104 : 1147-1153

[3] A. Monticelli , M .V.F Pereira ,and S. Granville, "Security constrained optimal power flow with post contingency corrective rescheduling", IEEE Transactions on Power Systems :PWRS-2, No. 1, pp.175-182., 1987.

[4] Deeb N, Shahidehpur S.M, Linear reactive power optimization in a large power network using the decomposition approach. IEEE Transactions on power system 1990: 5(2) : 428-435

[5] E. Hobson ,'Network consrained reactive power control using linear programming, ' IEEE Transactions on power systems PAS -99 (4) ,pp 868=877, 1980

[6] K.Y Lee, Y.M Park, and J.L Oritz, "Fuel -cost optimization for both real and reactive power dispatches", IEE Proc; 131C,(3), pp.85-93. 
[7] M.K. Mangoli, and K.Y. Lee, "Optimal real and reactive power control using linear programming”, Electr.Power Syst.Res, Vol.26, pp.1-10,1993.

[8] C.A. Canizares, A.C.Z.de Souza and V.H. Quintana " Comparison of performance indices for detection of proximity to voltage collapse ," vol. 11. no.3, pp.1441-1450, Aug 1996.

[9] K.Anburaja, "Optimal power flow using refined genetic algorithm", Electr. Power Compon.Syst , Vol. 30, 1055-1063,2002.

[10] D. Devaraj, and B. Yeganarayana, "Genetic algorithm based optimal power flow for security enhancement", IEE proc-Generation. Transmission and. Distribution; 152, 6 November 2005.

[11] A. Berizzi, C. Bovo, M. Merlo, and M. Delfanti, "A ga approach to compare or pf objective functions including secondary voltage regulation,"Electric Power Systems Research, vol. 84, no. 1, pp. $187-194,2012$.

[12] C.-F. Yang, G. G. Lai, C.-H.Lee, C.-T. Su, and G. W. Chang, "Optimal setting of reactive compensation devices with an improved voltage stability index for voltage stability enhancement," International Journal of Electrical Power and Energy Systems, vol. 37, no. 1, pp. $50-57,2012$.

[13] P. Roy, S. Ghoshal, and S. Thakur, "Optimal var control for improvements in voltage profiles and for real power loss minimization using biogeography based optimization," International Journal of Electrical Power and Energy Systems, vol. 43, no. 1, pp. 830 - 838, 2012.

[14] B. Venkatesh, G. Sadasivam, and M. Khan, "A new optimal reactive power scheduling method for loss minimization and voltage stability margin maximization using successive multi-objective fuzzy lp technique ,'IEEE Transactions on Power Systems, vol. 15, no. 2, pp. 844 -851, may 2000.

[15] W. Yan, S. Lu, and D. Yu, "A novel optimal reactive power dispatch method based on an improved hybrid evolutionary programming technique ,'IEEE Transactions on Power Systems, vol. 19, no. 2, pp. $913-918$, may 2004.

[16] W. Yan, F. Liu, C. Chung, and K. Wong, "A hybrid genetic algorithm interior point method for optimal reactive power flow," IEEE Transaction son Power Systems, vol. 21, no. 3, pp. 1163 1169, Aug. 2006.

[17] J. Yu, W. Yan, W. Li, C. Chung, and K. Wong, "An unfixed piece wise optimal reactive powerflow model and its algorithm for ac-dc systems ,"IEEE Transactions on Power Systems, vol. 23, no. 1 , pp. $170-176$, feb. 2008 .

[18] F. Capitanescu, "Assessing reactive power reserves with respect to operating constraints and voltage stability," IEEE Transactions on Power Systems, vol. 26, no. 4, pp. 2224-2234, Nov. 2011.

[19] Z. Hu, X. Wang, and G. Taylor, "Stochastic optimal reactive power dispatch: Formulation and solution method," International Journal of Electrical Power and Energy Systems, vol. 32, no. 6, pp. $615-621,2010$.

[20] A. Kargarian, M. Raoofat, and M. Mohammadi, "Probabilistic reactive power procurement in hybrid electricity markets with uncertain loads," Electric Power Systems Research, vol. 82, no. 1, pp. $68-80,2012$.

[21] M. J. Harris and W. V. Baxter, Thrsten Scheuermann, Simulation of Cloud Dynamics on Graphics Hardware, in Proc. ACM SIGGRAPH/EUROGRAPHICS Conf. Graphics Hardware (San Diego, 2003), pp. 92_101.

[22] L. Deyi and L. Changyu, Study on the universality of the normal cloud model, Eng. Sci.6 (2004) 28_34 (in Chinese).

[23] L. Deyi, L. Changyu and G. Wenyan, Proof of the heavy-tailed property of normal cloud model, Eng. Sci. 13(2011) 20_23 (in Chinese).

[24] L. Changeyu, L. Deyi and P. Lili, Uncertain knowledge representation based on cloud model, Comput. Eng. Appl. 40(2004) 32_35 (in Chinese). 
[25] Gao-Wei Yan And Zhan-Ju Hao A Novel Optimization Algorithm Based On Atmosphere Clouds Model ,International Journal of Computational Intelligence and Applications Vol. 12, No. 1 (2013) 1350002.

[26] Wu Q H, Ma J T. "Power system optimal reactive power dispatch using evolutionary programming", IEEE Transactions on power systems 1995; 10(3): 1243-1248 .

[27] S. Durairaj, D. Devaraj, P.S.Kannan, "Genetic algorithm applications to optimal reactive power dispatch with voltage stability enhancement”, IE (I) Journal-EL Vol 87, September 2006.

[28] D.Devaraj, "Improved genetic algorithm for multi - objective reactive power dispatch problem", European Transactions on electrical power 2007; 17: 569-581.

[29] P. Aruna Jeyanthy and Dr. D. Devaraj "Optimal Reactive Power Dispatch for Voltage Stability Enhancement Using Real Coded Genetic Algorithm", International Journal of Computer and Electrical Engineering, Vol. 2, No. 4, August, 2010 1793-8163.

\footnotetext{
*Corresponding author.

E-mail address: gklenin@ gmail.com
} 